\title{
A Descriptive Analysis of Tactical Casualty Care Interventions Performed by Law Enforcement Personnel in the State of Wisconsin, $2010-2015$
}

\author{
Chad M. Stiles, RN, NREMT-P, CCEMT-P; ${ }^{1}$ Christopher Cook, RN, EMT-P/Tactical; ${ }^{2}$ \\ Matthew D. Sztajnkrycer, MD, $\mathrm{PhD}^{3}$
}

1. Waukesha County Technical College, Pewaukee, Wisconsin USA

2. City of Pewaukee Fire Department, Pewaukee, Wisconsin USA

3. Mayo Clinic, Rochester, Minnesota USA

Correspondence:

Matthew D. Sztajnkrycer, MD, PhD

Associate Professor of Emergency Medicine

Mayo Clinic GE-GR-G410

$2001^{\text {st }}$ Street SW

Rochester Minnesota 55905 USA

E-mail: sztajnkrycer.matthew@mayo.edu

Conflicts of interest: none

Keywords: casualty; Emergency Medical Services; law enforcement; tactical; tourniquet

\section{Abbreviations:}

BA: buddy aid

CoTCCC: Committee on Tactical Combat Casualty Care

C-TECC: Committee on Tactical Emergency Casualty Care

EMS: Emergency Medical Services

SA: self-aid

TCCC: Tactical Combat Casualty Care

VA: victim aid

Received: April 20, 2016

Revised: August 1, 2016

Accepted: August 8, 2016

Online publication: February 21, 2017

doi:10.1017/S1049023X17000103

\begin{abstract}
Introduction: Based upon military experience, law enforcement has developed guidelines for medical care during high-threat conditions. The purpose of the current study was to provide a descriptive analysis of reported outcomes of law enforcement medical interventions. Methods: This was a descriptive analysis of a convenience sample of cases submitted to the Wisconsin Tactical Medicine Initiative (Wisconsin USA), after the provision of successful patient care, between January 2010 and December 2015. The study was reviewed by the Mayo Foundation Institutional Review Board (Rochester, Minnesota USA) and deemed exempt.

Results: Nineteen agencies submitted information during the study period. Of the 56 episodes of care reported, four (7.1\%) cases involved care provided to injured officers while 52 (92.9\%) involved care to injured civilians, including suspects. In at least two cases, on-going threats existed during the provision of medical care to an injured civilian. Law enforcement rendered care prior to Emergency Medical Services (EMS) arrival in all but two cases.

Conclusions: The current case series demonstrates the life-saving potential for law enforcement personnel trained and equipped under current Tactical Combat Casualty Care (TCCC)/ Committee on Tactical Emergency Casualty Care (C-TECC) tactical casualty care guidelines. Although originally developed to save the lives of wounded combat personnel, in the civilian sector, the training appears more likely to save victims rather than law enforcement personnel.
\end{abstract}

Stiles CM, Cook C, Sztajnkrycer MD. A descriptive analysis of tactical casualty care interventions performed by law enforcement personnel in the State of Wisconsin, 2010-2015. Prehosp Disaster Med. 2017;32(3):284-288.

\section{Introduction}

Numerous studies have evaluated the causes of possibly preventable death on the battlefield during modern military combat. ${ }^{1-3}$ Given that exsanguinating hemorrhage is estimated to be responsible for $35 \%$ of prehospital deaths, ${ }^{4,5}$ particular emphasis has been placed upon hemorrhage control. The Committee on Tactical Combat Casualty Care (CoTCCC; US Department of Defense; Arlington, Virginia USA) has developed specific, evidence-based Tactical Combat Casualty Care (TCCC) guidelines to improve battlefield survival. ${ }^{6,7}$ Operationalization of these guidelines at the unit level has resulted in dramatic decreases in case fatality rates and possibly preventable battlefield deaths. ${ }^{2,7,8}$

In 2014, 117 law enforcement officers died in the line of duty. ${ }^{9}$ According to US Federal Bureau of Investigation (Washington, DC USA) data, 51 of these officers died as a consequence of felonious assault, including seven officers who died during premeditated ambush situations. ${ }^{10}$ Another 13,654 officers sustained injuries as a consequence of felonious assault. In the face of these statistics, law enforcement has turned to its military counterparts to develop guidelines for the management of injury during conditions of ongoing or uncertain threat. ${ }^{11}$ One group at the forefront of guideline development and dissemination is the Committee on Tactical Emergency Casualty Care (C-TECC; Leesburg, Virginia USA). Working closely with CoTCCC, C-TECC has adapted military TCCC guidelines to the civilian law enforcement prehospital setting. ${ }^{12,13}$ 
Recognizing the need for such training, various agencies in Wisconsin (USA), including the Milwaukee Police Department and the Wisconsin Technical College System, have been providing training in tactical casualty care (TCCC and/or C-TECC) skills since 2007. The purpose of the current study was to provide a descriptive analysis of reported outcomes of law enforcement medical interventions after tactical casualty care skills training.

\section{Methods}

Study Design

This was a descriptive analysis of a convenience sample of cases submitted to the Wisconsin Tactical Medicine Initiative (Wisconsin USA), after the provision of successful patient care, between January 2010 and December 2015. The study was reviewed by the Mayo Foundation Institutional Review Board (Rochester, Minnesota USA) and deemed exempt.

\section{Study Population}

The study population included Wisconsin law enforcement personnel trained in TCCC/C-TECC by state-approved programs.

\section{Inclusion Criteria}

Cases were included in the study if law enforcement medical care:

- Occurred during the study time period;

- Was performed in accordance with TCCC/TECC guidelines;

- Was essential to providing an improved patient outcome by maintaining an airway, stabilizing breathing, and/or controlling bleeding; or

- May have contributed to sustaining the life of a patient or improving patient outcome.

\section{Exclusion Criteria}

Cases were excluded if care recorded in the submitted narratives did not meet inclusion criteria or was deemed to be unrelated to tactical casualty care interventions.

\section{Database Creation and Primary Data Analysis}

Descriptive narratives of patient care episodes were voluntarily submitted to a single point of contact (CMS) at the Wisconsin Tactical Medicine Training Initiative. Data were subsequently abstracted by a single investigator (MDS). Data accuracy was dependent upon the provided voluntary narratives and could not be further validated. Specific data elements collected included agency name, nature of care (self-aid [SA], buddy aid [BA], or victim aid [VA]), specific nature of victim (suspect or crime victim), nature of event (eg, armed robbery), presence of multiple victims, gender of victim, mechanism of injury, care provided under threat (if documented), primary anatomic location of injury, identity of injured blood vessel (if documented), presence or absence of suspected tension pneumothorax physiology, specific interventions performed, use of commercial versus improvised interventions, TCCC/C-TECC training level, presence of Emergency Medical Services (EMS) on scene prior to officer arrival, and outcomes. All narratives were de-identified in terms of both victims and providers. Abstracted data elements were entered into a Microsoft Excel database (Microsoft Excel for Mac 2011, v 14.5.3; Redmond, Washington USA) and descriptive analyses, including summary statistics, were generated.
Results

As part of the Wisconsin Tactical Medicine Training Initiative, more than 4,570 emergency response personnel received tactical casualty care TCCC/C-TECC training between 2007 and 2015. Training varied from 1-hour to 8-hour "awareness" level courses to a 40-hour Tactical EMS curriculum. Between January 2010 and December 2015, data regarding successful medical response were submitted by 19 agencies (Table 1 ).

Of the 56 episodes of care reported, four (7.1\%) cases involved care provided to injured officers ("buddy aid/BA") while 52 (92.9\%) involved care to injured civilians, including suspects (two patients). No cases of SA were documented. In at least two cases, on-going threats existed during the provision of medical care; the patients in both cases were injured civilians.

The majority of events involved penetrating trauma. Twentytwo patients sustained gunshot wounds, while 27 sustained stab wounds (Figure 1). A single patient received tactical casualty care after suffering a medical emergency. Location of injury is provided in Figure 2; the majority of injuries amenable to tactical casualty care occurred on the extremities. Specifically identified blood vessels included femoral artery (three patients), carotid artery (one patient), and jugular vein (one patient). Eight events involved multiple patients, and two were classified as active shooter events. Patient gender was identified in 42 cases, of which 38 (90.5\%) were identified as male.

Law enforcement rendered care prior to EMS arrival in all but two cases (96.4\%); in these cases, EMS either required but did not have tourniquets, or was unable to control bleeding with a single tourniquet. Specific tactical casualty care interventions are listed in Table 2. Thirteen patients received two interventions while a single patient received three and four interventions, respectively. One patient developed evidence of tension pneumothorax after placement of an unvented chest seal. Improvised tourniquets were documented in seven episodes of care, of which six were unsuccessful, requiring transition to commercial tourniquets.

\section{Discussion}

In the aftermath of Operation Gothic Serpent, the special operations mission in Mogadishu, Somalia, the military revised its approach to battlefield medical care. An analysis of possibly preventable deaths during the Vietnam War led to the development of prehospital trauma care protocols appropriate for the threats encountered in modern combat. ${ }^{6}$ These protocols focused upon mitigating the three most common possibly preventable causes of death and addressed initial SA and subsequent BA. The resultant TCCC paradigm continues to save lives down-range. ${ }^{2,8} \mathrm{~A}$ study of the TCCC-trained, $75^{\text {th }}$ Ranger Regiment found that $1.7 \%$ of regimental fatalities died of wounds, compared with $5.8 \%$ in the larger US military population $(\mathrm{P}=.02) .^{2}$ No Ranger fatality died from wounds potentially survivable through additional prehospital interventions. The TCCC training proved so effective that although exsanguinating hemorrhage remains the leading cause of possibly preventable combat death, fatalities from extremity hemorrhage decreased from $60 \%$ to $13.5 \%{ }^{1}$

Excluding the events of September 11, 2001, 505 law enforcement officers died as a consequence of felonious assault between 2005 and 2014, representing an average of 51 deaths per year. ${ }^{10}$ During the same time period, another 563,030 officers were assaulted on duty, representing an assault every 9.3 minutes, on average. Unprovoked ambush situations were responsible for $7.1 \%$ of deaths and $0.4 \%$ of assaults. Firearms were the most 


\begin{tabular}{|c|c|}
\hline Agency & Patient Encounters \\
\hline Milwaukee Police Department & 23 \\
\hline Elm Grove Police Department & 6 \\
\hline Green Bay Police Department & 6 \\
\hline Waukesha County Sheriff's Office & 2 \\
\hline Town of Brookfield Police Department & 1 \\
\hline Walworth County Sheriff's Office & 3 \\
\hline Madison Police Department & 3 \\
\hline Dane County Sheriff's Office & 2 \\
\hline Wausau Police Department & 2 \\
\hline Sauk County Sheriff's Office & 1 \\
\hline Green County Sheriff's Office & 1 \\
\hline Winnebago County Sheriff's Office & 1 \\
\hline Ozaukee County Sheriff's Office & 1 \\
\hline Chippewa Falls Police Department & 1 \\
\hline Sheboygan County Sheriff's Office & 1 \\
\hline Beaver Dam Police Department & 1 \\
\hline Shawano County Sheriff's Office & 1 \\
\hline Lafayette County Sheriff's Office & 1 \\
\hline
\end{tabular}

Table 1. Wisconsin Agencies Providing Data and Number of Patient Encounters Reported

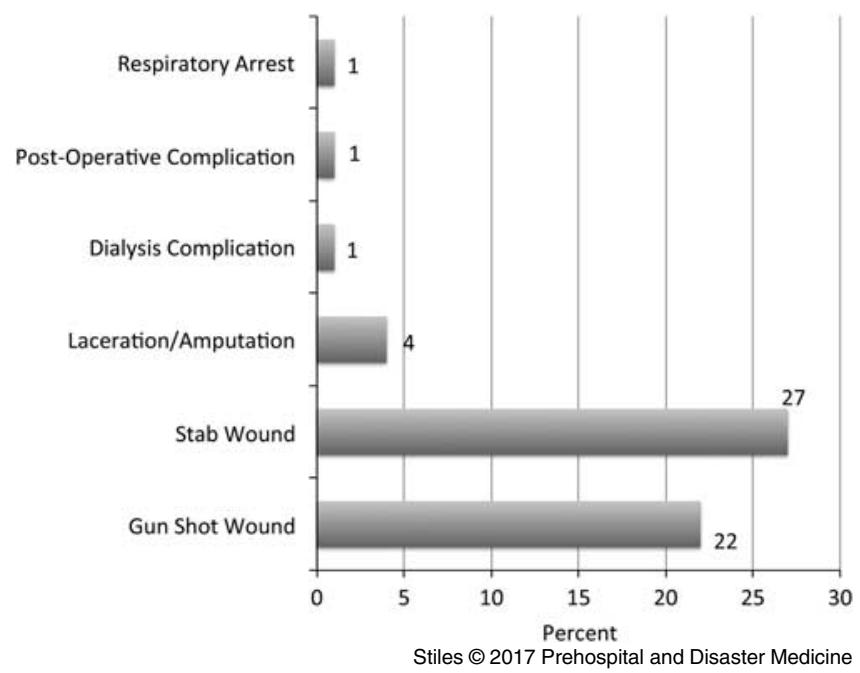

Figure 1. Mechanism of Injury.

commonly used weapons in fatal assaults, representing $92.0 \%$ of weapons used.

Despite these stark figures, until recently, little guidance has been available to law enforcement for the management of injuries during conditions of active threat. Conventional civilian

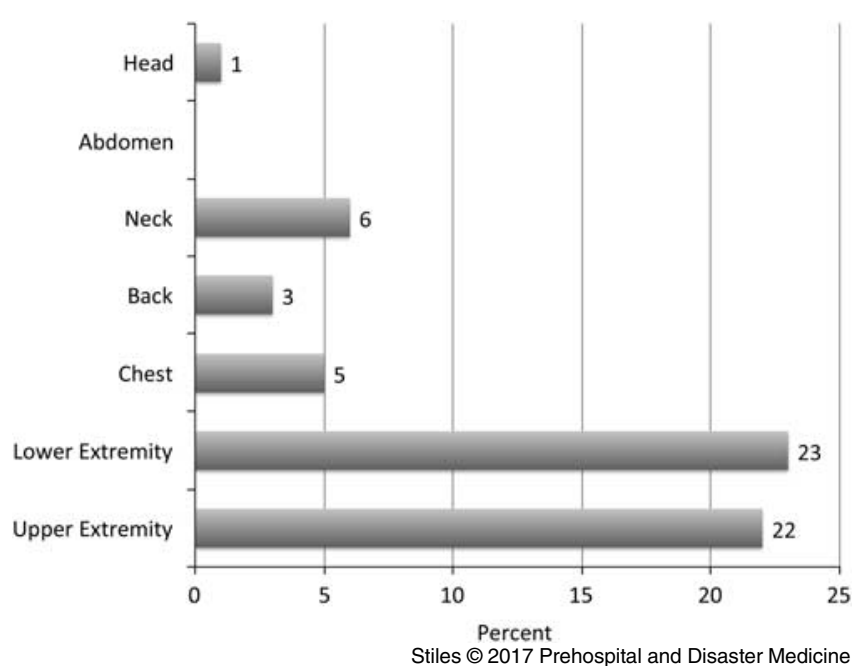

Figure 2. Location of Injury.

\begin{tabular}{|l|c|}
\hline Intervention & Number \\
\hline Tourniquet & 42 \\
\hline Hemostatic Agent & 15 \\
\hline Chest Seal & 7 \\
\hline Pressure Dressing & 5 \\
\hline Nasopharyngeal Airway & 1 \\
\hline
\end{tabular}

Table 2. Tactical Casualty Care Interventions Performed by Law Enforcement Personnel.

prehospital care techniques are predicated upon scene safety, and as such, have limited utility during rapidly evolving circumstances, including response to active shooter events. As a consequence, TCCC methodology has increasingly been adopted by law enforcement to fill this practice gap. ${ }^{12,13}$ The C-TECC has specifically adapted TCCC to the law enforcement environment, providing an operational framework for SA/BA under conditions of active threat.

The Wisconsin Technical College System and Milwaukee Police Department began teaching TCCC in 2007, subsequently transitioning to C-TECC in Spring 2011. To date, more than 4,570 emergency response personnel have received training, ranging from the basic awareness level to advanced tactical EMS curriculum. The current data do not permit assessment of training in order to determine the optimal training regimen/duration, but do provide a case series demonstrating the life-saving potential for this training.

Although tactical casualty care training focuses upon SA/BA under conditions of active threat, the current study demonstrates that this training is more likely to be used on non-law enforcement personnel, including both victims and perpetrators of violence. Only four cases (7.1\%) of BA were documented; tourniquet application to an officer with lower extremity gunshot wound, tourniquet application to two officers stabbed in the lower extremities while descending an open spiral staircase, and tourniquet application to an officer with a partial lower extremity amputation secondary to motor vehicle accident. These results suggest that VA 


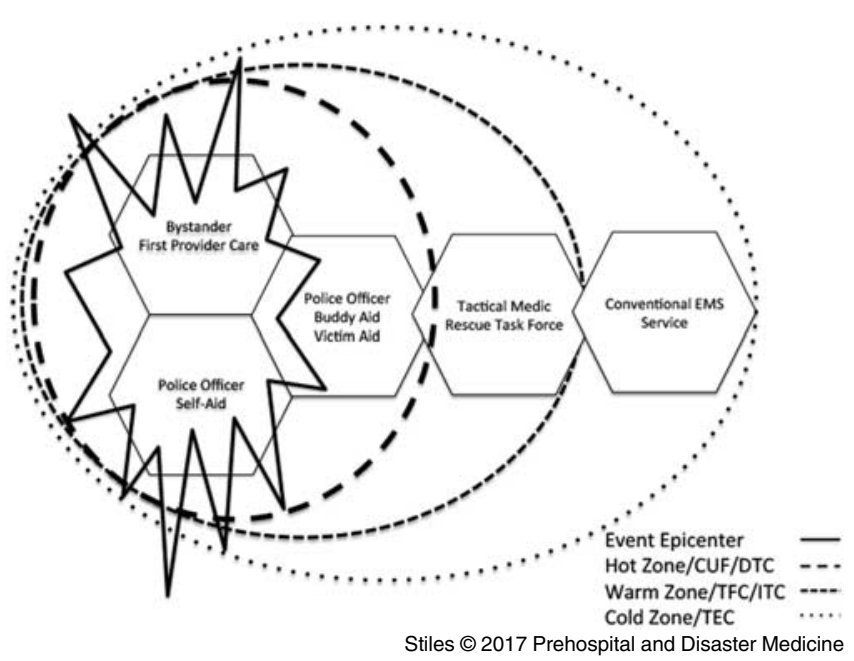

Figure 3. Proposed Tactical Casualty Care Chain of Survival. Abbreviations: CUF, Care Under Fire; DTC, Direct Threat Care; EMS, Emergency Medical Services; ITC, Indirect Threat Care; TEC, Tactical Evacuation Care; TFC, Tactical Field Care.

will be the primary use of tactical casualty care training. Of particular note, given recent high-profile, officer-involved shootings in which video appeared to demonstrate either delay or absence of medical care immediately after the event, two of 29 individuals receiving life-saving interventions for wounds sustained as a consequence of felonious action were suspects. ${ }^{14,15} \mathrm{~A}$ suggested designation of SA/BA/VA both more accurately reflects the reality of use and highlights the capability of this training to increase community resiliency by expanding the chain of survival during high-threat events (Figure 3).

The current study suggests that tactical casualty care training, coupled with appropriate equipment, had the potential to save lives. In keeping with the emphasis of both TCCC and C-TECC on extremity hemorrhage control, $82.1 \%$ of patients in the current case series sustained extremity injuries. Forty-two patients received tourniquets while 15 received hemostatic dressings. Only one of seven improvised tourniquets functioned effectively, highlighting the importance of appropriate equipment in the delivery of life-saving hemorrhage control.

Chest seals were used in seven patients. Controversy exists about the use of chest seals for penetrating chest trauma in the combat setting. ${ }^{16,17}$ Although such seals may improve the mechanics of breathing in individuals with penetrating chest trauma, thereby temporizing the effects until definitive treatment is rendered, concern exists for iatrogenic development of a tension pneumothorax. During one response, the first arriving officer encountered three shooting victims, one of whom sustained a gunshot wound below the right breast with an exit wound below the right scapula. The patient had two unvented chest seals placed and developed increasing respiratory distress. The officer considered needle decompression, but deferred the procedure due to EMS arrival and transfer of care. Twenty-three minutes after officer arrival, EMS arrived and transported the patient to a trauma center, where she received needle thoracostomy followed by tube thoracostomy. Although current TCCC and C-TECC guidelines recommend the use of chest seals for the management of open pneumothorax, recent changes recommend the use of vented chest seals, where available, to mitigate the risk of tension pneumothorax. ${ }^{16}$ If unavailable, guidelines recommend that unvented seals be "burped" or removed if patients develop clinical evidence of a tension pneumothorax.

Events in Newtown (Connecticut USA), Aurora (Colorado USA), San Bernardino (California USA), and Paris (France) have highlighted the importance of law enforcement medical response in the triage, treatment, and transportation of victims of active shooter and complex attacks. Victims in the Aurora theater shooting were treated and transported by law enforcement personnel after EMS refused to enter an unsecured environment. ${ }^{18}$ The Hartford Consensus specifically identified the importance of law enforcement training in hemorrhage control, including tourniquets and hemostatic dressings. ${ }^{19,20}$ This recommendation has been highlighted and expanded to the concept of lay-person first provider care as part of the "Stop the Bleed" initiative. ${ }^{21}$ During the complex attacks in Paris, the need for tourniquets was so great that many EMS providers returned without belts. ${ }^{22}$ Eight of the events in the current case series involved multiple victims, while two were classified as active shooter events.

\section{Limitations}

The current study suffers from several limitations. First, the patients included in the study represent a convenience sample of patients voluntarily reported to the Wisconsin Tactical Medicine Initiative between January 2010 and December 2015. As a consequence, the study is biased towards individuals and agencies more invested in tactical casualty care training.

The study specifically evaluated "saves," and therefore is biased towards positive outcomes. It may be that tactical casualty care interventions were performed in some circumstances, but due to perceived negative outcomes, were not reported. Similarly, this study would miss situations in which this training would have been appropriate but was not employed. A national survey of law enforcement personnel identified situations in which tourniquets or hemostatic agents could have been used but were not. ${ }^{23}$

The information provided for each circumstance was a summary narrative, and therefore, did not capture all pertinent information in all cases, including number of attempts and complications or difficulties encountered. Although the cases submitted represent perceived saves, the limited narratives by non-medical personnel do not allow a comprehensive analysis of actual efficacy and improved outcomes in terms of survival and morbidity compared with conventional EMS. In terms of this latter concern, data suggest that tourniquets save lives most effectively when applied before the development of overt shock. ${ }^{24}$ Studies also have shown that in cases of penetrating trauma, decreased time to definitive care is associated with improved survival outcomes. ${ }^{25-27}$

\section{Conclusions}

The current case series demonstrates the life-saving potential for law enforcement personnel trained and equipped under current TCCC/C-TECC tactical casualty care guidelines. Although originally developed to save the lives of wounded combat personnel, in the civilian sector, the training is more likely to save victims rather than law enforcement personnel. The identified skillsets worked in both single victim encounters and masscasualty events, including active shooter events. Analogous to the military experience, a comprehensive law enforcement trauma 
registry is required to allow definitive analysis of interventions and subsequent outcomes. With concerns for complex high-threat situations increasing both in the United States and throughout the

\section{References}

1. Eastridge BJ, Mabry RL, Seguin P, et al. Death on the battlefield (2001-2011): implications for the future of combat casualty care. J Trauma Acute Care Surg. 2012; 73(6 Suppl 5):S431-S437.

2. Kotwal RS, Montgomery HR, Kotwal BM, et al. Eliminating preventable death on the battlefield. Arch Surg. 2011;146(12):1350-1358.

3. Bellamy RF. The causes of death in conventional land warfare: implications for combat casualty care research. Mil Med. 1984;149(2):55-62.

4. Evans JA, van Wessem KJP, McDougall D, Lee KA, Lyons T, Balogh ZJ. Epidemiology of traumatic deaths: comprehensive population-based assessment. World J Surg. 2010;34(1):158-163.

5. Kauvar DS, Lefering R, Wade CE. Impact of hemorrhage on trauma outcome: an overview of epidemiology, clinical presentations, and therapeutic considerations. J Trauma. 2006;60(6 Suppl):S3-11.

6. Butler FK Jr, Hagmann J, Butler EG. Tactical combat casualty care in special operations. Mil Med. 1996;161(Suppl 3):3-16.

7. Butler FK Jr, Holcomb JB, Giebner SD, McSwain NE, Baglan J. Tactical combat casualty care 2007: evolving concepts and battlefield experience. Mil Med. 2007; 172(11 Suppl):1-19.

8. Tien HC, Jung V, Rizoli SB, Acharya SV, MacDonald JC. An evaluation of tactical combat casualty care interventions in a combat environment. J Am Coll Surg. 2008; 207(2):174-178.

9. National Law Enforcement Officer Memorial Fund. Officer Deaths by Year. http:// www.nleomf.org/facts/officer-fatalities-data/year.html. Accessed March 1, 2016.

10. US Department of Justice. Federal Bureau of Investigations. Criminal Justice Information Services Division. Uniform Crime Reports. About Law Enforcement Officers Killed and Assaulted, 2014. https://www.fbi.gov/about-us/cjis/ucr/leoka/ 2014. Accessed March 1, 2016.

11. Butler FK, Carmona R. Tactical combat casualty care: from the battlefields of Afghanistan and Iraq to the streets of America. Tactical Edge. 2012;27:86-91.

12. Callaway DW, Smith ER, Shapiro G, Cain JS, McKay SD, Mabry RL. The Committee for Tactical Emergency Casualty Care (C-TECC): evolution and application of TCCC guidelines to civilian high threat medicine. J Spec Oper Med. 2011;11(3):94-99.

13. Callaway DW, Smith ER, Cain J, et al. Tactical Emergency Casualty Care (TECC): guidelines for the provision of prehospital trauma care in high threat environments. J Spec Oper Med. 2011;11(3):104-122.

14. Swaine J. Second officer in Walter Scott video sued over alleged attack on handcuffed man. The Guardian. April 9, 2015. http:/www.theguardian.com/us-news/2015/apr/ 09/second-officer-walter-scott-video-sued-stomping. Accessed February 29, 2016. world, a trauma registry should be considered a national priority in advancing the field of law enforcement tactical medical care and public health.

15. Chicago Police Shooting Video Sparks Protests. CBS News/Associated Press. http:// www.cbsnews.com/news/laquan-mcdonald-chicago-police-shooting-video-sparks-protests. Published November 25, 2015. Accessed February 29, 2016.

16. Butler FK, Dubose JJ, Otten EJ, et al. Management of open pneumothorax in tactical combat casualty care: TCCC guidelines change 13-02. J Spec Oper Med. 2013; 13(3):81-86.

17. Kotwal RS, Butler FK, Edgar EP, et al. Saving lives on the battlefield: a joint trauma system review of pre-hospital trauma care in combined joint operating area-Afghanistan (CJOA-A). Published January 30, 2013. http://www.jsomonline. org/TCCC/ CENTCOM\%20Prehospital\%20Final\%20Report\%20 130130.pdf. Accessed February 29, 2016.

18. Baker M. Colorado shooting: police pleaded for ambulances on night of Aurora movie theater massacre. Huffington Post. July 27, 2012. http://www.huffingtonpost.com/ 2012/07/ 27/colo-shooting-police-plea_n_1709407.html. Accessed February 29, 2016.

19. Jacobs LM, McSwain N, Rotondo M, et al. Joint Committee to Create a National Policy to Enhance Survivability from Intentional Mass Casualty and Active Shooter Events. Improving survival from active shooter events: The Hartford Consensus. Bull Am Coll Surg. 2013;98(6):14-16.

20. Jacobs LM. Joint Committee to Create a National Policy to Enhance Survivability from Intentional Mass Casualty and Active Shooter Events. The Hartford Consensus III: implementation of bleeding control: if you see something do something. Bull Am Coll Surg. 2015;100(Suppl 1):40-46.

21. Department of Homeland Security. Stop the Bleed. Published November 20, 2015. https:/www.dhs.gov/stopthebleed. Accessed February 29, 2016.

22. Hirsch M, Carli P, Nizard R, et al. The medical response to multi-site terrorist attacks in Paris. Lancet. 2015;386:2535-2538.

23. Aberle SJ, Dennis AJ, Landry JM, Sztajnkrycer MD. Hemorrhage control by law enforcement personnel: a survey of knowledge translation from the military combat experience. Mil Med. 2015;180(6):615-620.

24. Kragh JF Jr, Littrel ML, Jones JA, et al. Battle casualty survival with emergency tourniquet use to stop limb bleeding. J Emerg Med. 2011;41(6):590-597.

25. Johnson NJ, Carr BG, Salhi R, Holena DN, Wolff C, Band RA. Characteristics and outcomes of injured patients presenting by private vehicle in a state trauma system. Am J Emerg Med. 2013;31(2):275-281.

26. Seamon MJ, Fisher CA, Gaughan J, et al. Prehospital procedures before emergency department thoracotomy: "scoop and run" saves lives. J Trauma. 2007;63(1):113-120.

27. Band RA, Salhi RA, Holena DN, Powell E, Branas CC, Carr BG. Severity-adjusted mortality in trauma patients transported by police. Ann Emerg Med. 2014;63(5): 608-614. 